\title{
Supporting problems at an island mining face in shanxi, China. Case study based on field observation
}

\author{
Xiaowe Feng \\ China University of Mining and Technology, China
}

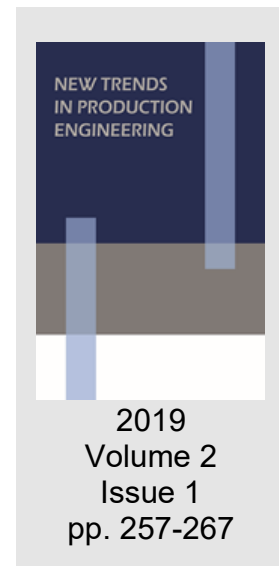

Date of submission to the Editor: 05/2019

Date of acceptance by the Editor: 07/2019

\section{INTRODUCTION}

In the human's history of coal mining, there have many approaches to find problems, discuss the problems, and then solve the problems, this is a process through which the industry continuously upgrade itself with new theories and materials. Right now in modern days, some famous approaches include analytical solution, numerical solution, experimental solution and field observations are parallel with each other. Many practitioners proposed their solutions with the assistance of at least one approach or more to defend their ideologies (Aziz et al. 2016). Nonetheless, for coal mining engineers, field observation is still and will be still the most straightforward, the most effective, the most economic and the most technique-sound approach to discover engineering problems and provide solutions (Li 2010; Kang et al. 2013). In this paper, field observation was conducted in Fujiaao Coalmine, Shanxi province, China, and some supporting problems are discussed and some standpoints regarding solutions are proposed.

\section{GEOLOGY AND SUPPORTING PATTERN Geology}

The trial was conducted at Fujiaao Coal Mine, it locates in Pu county, Linfen City, in Shanxi Provence. The annual coal production capacity is $1,800,000$ tons and the main coal mining method is longwall mechanized full-seam mining method.

The elevation of coal seam is $+1220 \mathrm{~m}$, the ground elevation is $+1512 \sim+1340$ $\mathrm{m}$, and the mining elevation is $+1247 \sim+1186 \mathrm{~m}$. Fig. 1 presents the layout of coal mining face 105, 107 and 109, supporting problems in the entries affiliated to face 107 are the study object in this study, namely head entry 107 and tail entry 107. Face 107 locates at the middle of the north side of the coal field, and the opening cut borders the boundary of coal field. Its eastern side was gob area of face 109 and its estern side was gob area of face 105. 


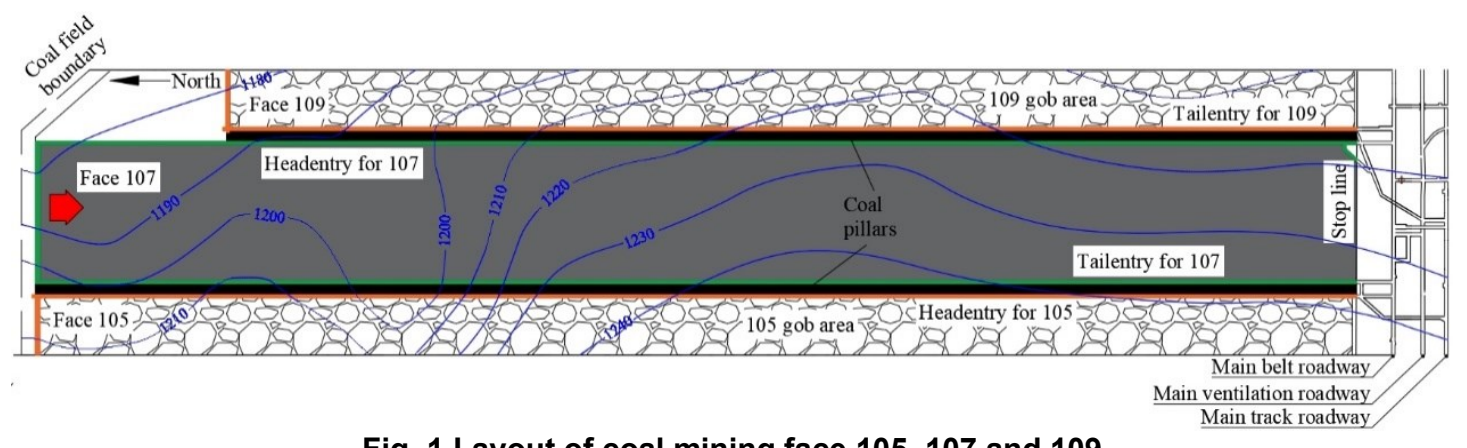

Fig. 1 Layout of coal mining face 105, 107 and 109

The strike length of the head entry and tail entry is $1903 \mathrm{~m}$ and the length of the face is $191 \mathrm{~m}$, burial depth of coal seam 107 can range from $124 \mathrm{~m}$ to $292 \mathrm{~m}$. Therefore, face 107 belongs a typical island working face and it certainly suffers comparatively high stress from overlaying strata, and a scientific selection of support scheme is critical to the deformation controlling effects in the head entry 107 and tail entry 107. Plus, two coal pillars are retained with a width of $15 \mathrm{~m}$ to isolate entries of face 107 with 109 gob area and 105 gob area. Undoubtedly the wise choose of pillar width also plays an important role in regards to the balance between a higher extraction rate and a safe entries space.

Fig. 2 gives the geologic column for coal seam 11\#. As can be seen, coal seam thickness is $2.7 \mathrm{~m}$ and overlaid by a layer of mudstone with thickness of $8.35 \mathrm{~m}$, above the mudstone there finds a layer of fine sandstone with thickness of 5.02 $\mathrm{m}$. Strata beneath the coal seam is mudstone $(4.49 \mathrm{~m})$, aluminum mudstone $(2.20 \mathrm{~m})$, and limestone $(2.13 \mathrm{~m})$, successively. Overall, the burial depth of coal seam is $141.79 \mathrm{~m}$.

\begin{tabular}{|c|c|c|c|c|}
\hline & $\begin{array}{c}\text { Accumulated } \\
\text { thickness (m) }\end{array}$ & $\begin{array}{l}\text { Layer } \\
\text { thickness (m) }\end{array}$ & Lithology & Brief description \\
\hline & 130.74 & 5.02 & Fine sandstone & $\begin{array}{l}\text { Gray, consist mainly of quartz and } \\
\text { secondly of fledspar }\end{array}$ \\
\hline 139.09 & 8.35 & Mudstone & $\begin{array}{l}\text { Dark gray, rich in fossilized plant } \\
\text { fragments, even fracture }\end{array}$ \\
\hline 141.79 & 2.70 & Coal & Black, bright coal \\
\hline & 146.28 & 4.49 & Mudstone & $\begin{array}{l}\text { Dark gray, rich in fossilized plant } \\
\text { fragments, even fracture }\end{array}$ \\
\hline & 148.48 & 2.20 & $\begin{array}{l}\text { Aluminum } \\
\text { mudstone }\end{array}$ & $\begin{array}{l}\text { Gray, rick in fossilized plant } \\
\text { fragments, have slippery feeling }\end{array}$ \\
\hline & 150.61 & 2.13 & $\begin{array}{l}\text { Limestone } \\
\text { Light gray, rick in animal fossil. }\end{array}$ \\
\hline
\end{tabular}

Fig. 2 Geologic column for coal seam 11\#

\section{Supporting pattern}

The size of head entry 107 and tail entry 107 are identical and the width*height is $4600 \mathrm{~mm} \cdot 2900 \mathrm{~mm}$. Supporting pattern for the head entry 107 and tail entry 107 also keeps identical and is drawn in Fig. 3.

For the roof support, three roof bolt and two cable bolt overlie the W-shaped steel belt through the holes machined on the belt, two corner bolts are installed at an angle of $75^{\circ}$ with the horizontal direction and their respective distance to the rib is $400 \mathrm{~mm}$. 


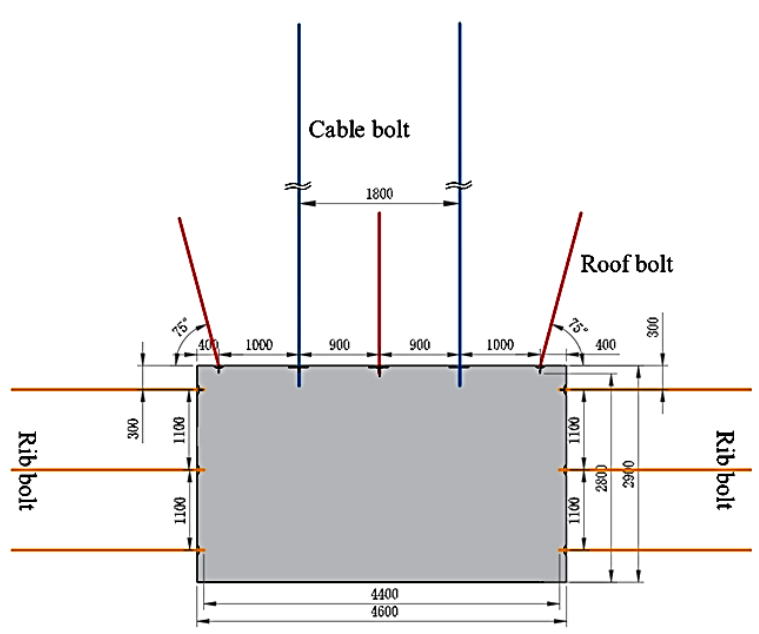

(a)

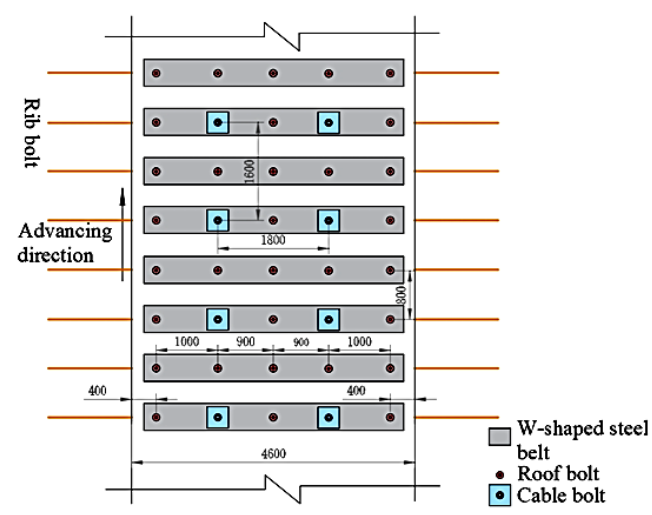

(b)

Fig. 3 Cross-section supporting pattern (a) and top view of the supporting pattern (b)

The holes distance on the steel belt is $1000 \mathrm{~mm}, 900 \mathrm{~mm}, 900 \mathrm{~mm}$, and 1000 $\mathrm{mm}$, and the holes bilateral the central hole are set for cable bolts. Dimension for the steel belt is $250 \mathrm{~mm} \cdot 4200 \mathrm{~mm}$ with a thickness of $3 \mathrm{~mm}$. Dimension for roof bolt is $20 \mathrm{~mm}$ in diameter and $2000 \mathrm{~mm}$ in length, cable bolt is composed of seven indented wires that are twisted around a centre wire, the diameter of cable bolt is $17.8 \mathrm{~mm}$ and the length is $8200 \mathrm{~mm}$. For the rib side, three bolts are installed altogether at each side and they are also vertically arranged to the rib. Bolts at each side are pinned on the ladder-shaped steel beam with distance to the roof set respectively as $300 \mathrm{~mm}, 1400 \mathrm{~mm}$, and $2500 \mathrm{~mm}$. Dimension for rib bolts is $20 \mathrm{~mm}$ in diameter and $2000 \mathrm{~mm}$ in length that is identical to roof bolts. Attached face places for roof bolts and rib bolts are spherical domed with a diameter of $130 \mathrm{~mm}$ and thickness of $10 \mathrm{~mm}$. Steel mesh covers on the bare roof and bare ribs and then fixed by steel belts, cable bolts, and bolts. The diameter for the mesh bar is $2.8 \mathrm{~mm}$ and the dimension for a whole mesh unit is $4600 \mathrm{~mm} \times 1100 \mathrm{~mm}$. Overall, the distance between steel belts is $800 \mathrm{~mm}$ and the distance between the neigh boring rows of cable bolts is $1600 \mathrm{~mm}$, as labeled in Fig. 3b.

In Fig. 4, the practical support patterns are presented, which demonstrate a more straightforward interpretation to the explanations aforementioned in regards to Fig. 3.

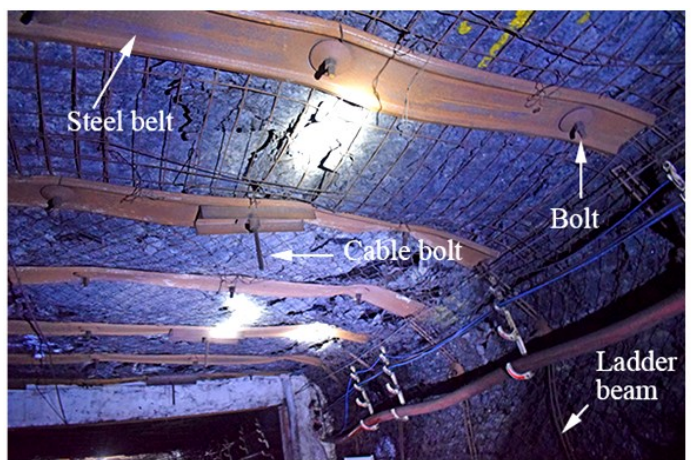

(a)

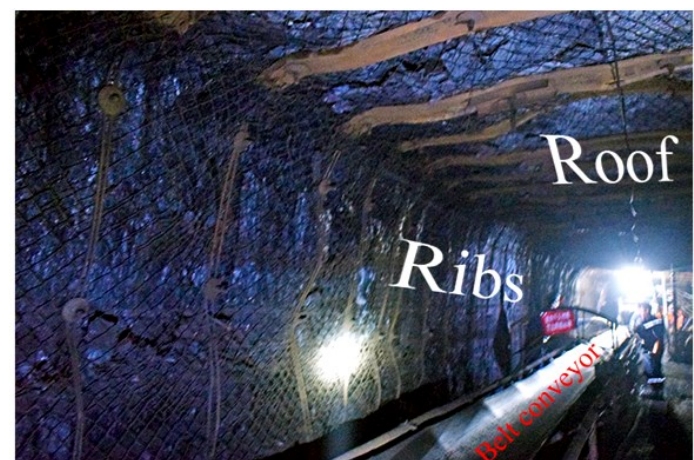

(b)

Fig. 4 Practical support patterns in entries, (a) specific interpretation on support components, (b) an overall perspective of headentry 107 (belt conveyor arranged for coal transportation) 


\section{PROBLEMS DESCRIPTION}

Under the support pattern illustrated in section 2.2, both of the head entry for 107 and the tail entry for 107 suffers severe deformation problems.

The most prominent one is the roof subsidence, the roof subsistence occurs a short time after excavation, even without the disturbance caused by advancing of coal mining face. This phenomenon can be observed in Fig. 5a,b, which exhibit failure pattern nearby the right corner of roof (the left corner was difficulty to be photographed due to the arrangement of ventilation pipe on the left side). Field observation indicates that roof subsidence happens in an integral measure and drops to the floor. In Fig. 5a, the steel belt is bended due to the dropping of the roof and the locking effect of the corner bolt. A more serious situation is presented in Fig. 5b, coal mass in the roof is cracked and the roof clearly subsides towards the floor. Corner bolt sinks into coal mass and is unobservable, mesh originally attached at the upper corner of ribs is also buried into cracked subsided coal mass.

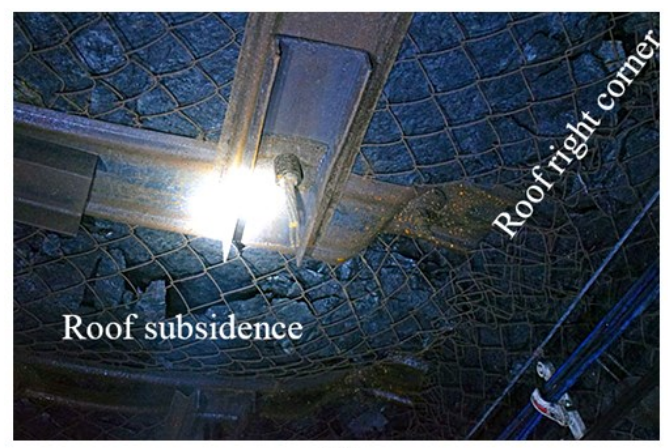

(a)

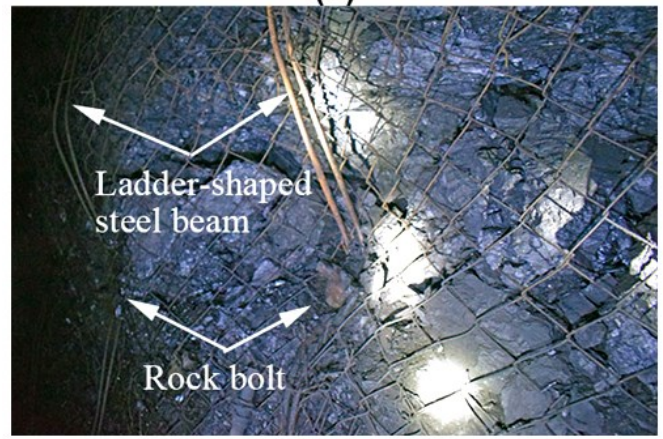

(c)

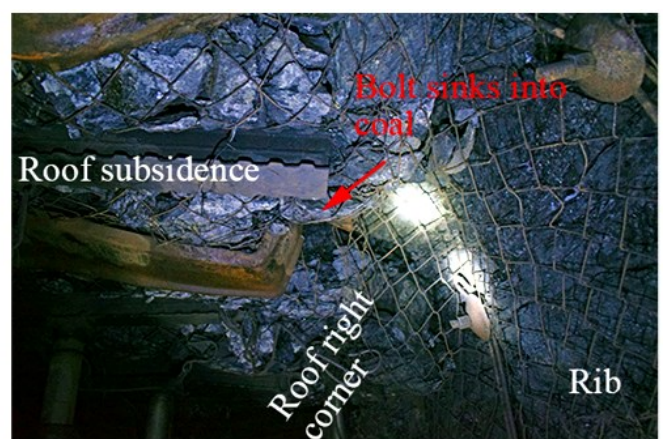

(b)

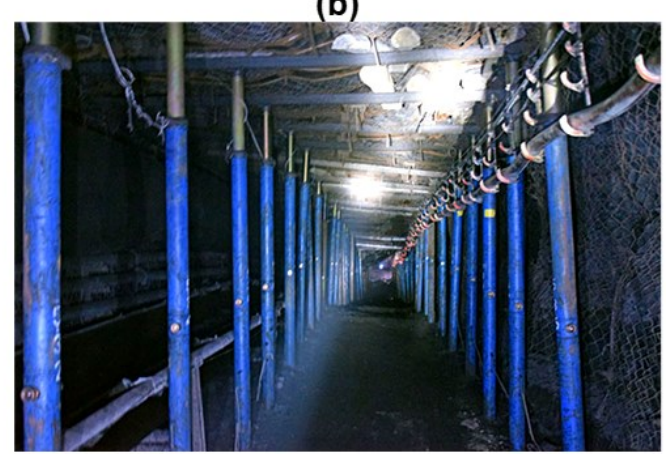

(d)

Fig. 5 Entries' breakage morphology (a-c) and auxiliary strengthening measure (d)

As for the deformation of ribs, however, most sections shows no obvious bulking phenomenon and ribs deformation is not very obvious. Considering the supporting pattern on the ribs, the support strength should be not very high. Nevertheless, field observation indicates that seldom has a bolting system failed or has a ladder-shaped steel beam ruptured. It proves that the stability of coal ribs can be guaranteed under its own integrity and reinforcement provided by support components. Therefore the retained coal pillar width is also reasonable (15 $\mathrm{m}$ as stated in section 2.1). However, areas with overlarge roof subsidence is sometimes accompanied by floor heave, which further leads to bulking of ribs as exampled in Fig. 5c. 
In order to improve the support effects of the entries, the coal mine engineers utilize single props to resist the subsidence of the roof, as shown in Fig. $5 \mathrm{~d}$. This method functions in some areas, but the effects is limited when water spilling/leaching is encountered. Water will greatly soften the floor and will then lead to the sink of the single props, afterwards, the holding power of the props will be reduced. Oftentimes the effect is still limited even base boards are applied beneath the props. Moreover, the recovery procedure of props must be carried out in advance when coal cutting face approaches, which further aggregates the working load of workers and increases the operational procedures, a highefficiency coal production requirement is difficult to be attained.

\section{PROBLEMS DISCUSSION AND SOLUTIONS}

\section{Strength mismatch in bolting system}

By referring Fig. 3, it can be seen that the bolting system consists of exterior nut and face place and also interior bolt and resin annulus. Based on field observation, the authors noticed that barely are the face plates distorted and this phenomenon is especially prominent for those bolts installed on the roof. Then why the roof deformation cannot be controlled? some photos showing the actual failures are listed in Fig. 6. As can be seen, though the face place is intact, the belt always breaks due to penetration of face plate, not matter the assorted component is rock bolt (Fig. 6a) or cable bolt (Fig. 6b), oftentimes steel belt can be torn (Fig. 6c). This face plate is referred as 'sole domed plate' in the following text.

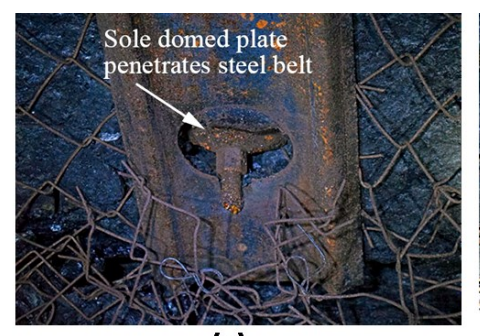

(a)

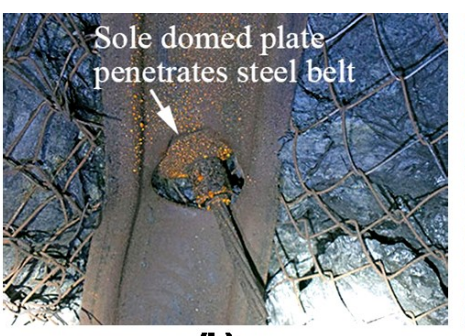

(b)

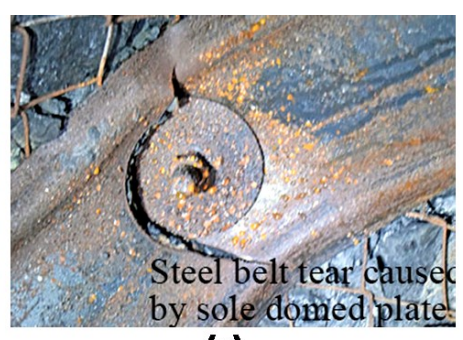

(c)

Fig. 6 photos showing penetration of face plate through steel belt

In regards to the shape of the face plate, it cannot, strictly speaking, be treated as a standard face plate due to its sole domed configuration. The diameter for the sole domed plate is $130 \mathrm{~mm}$, and the stress distribution between the steel belt and sole domed plate is schematically sketched in the left side of Fig. 7 .
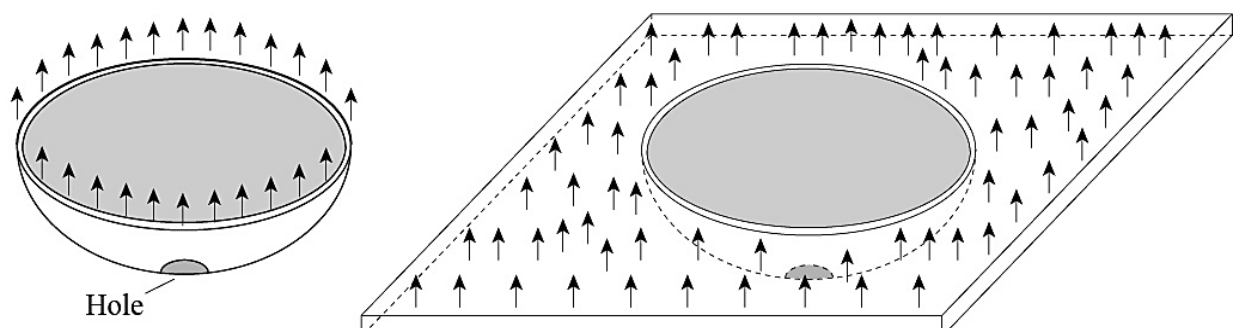

Fig. 7 Stress distribution between face plate and steel belt for different types 
As can be clearly noticed, the stress altogether concentrates on the edge of the sole domed plate. Under such a circumstance, the bearing strength of the bolting system is not determined by the loading properties of the bolt, neither by the nut, or resin annulus, or sole domed plate mentioned above. It is actually determined by the anti-penetration capacity of the steel belt, considering the thin thickness ( $3 \mathrm{~mm}$ ) of the steel belt, then it is without any doubt that the strength mismatch between steel belt and face plate becomes a decisive factor and the effectiveness of belt is greatly reduced. As demonstrated by failure examples in Fig. 6.

Practitioners apply steel belt to the roof support mainly for enlarging the stress distribution area on the roof and the stress is just sourcing from bearing load of bolting system. In this trial, the contact area between sole domed plate and steel belt is circular arranged, under similar loading, the plate is easy to penetrate through the belt and then sink into coal mass, thereby the actual bearing ability is limited.

On the right side of Fig. 7, stress distribution of a normal face plate is presented. Unlike sole domed plate, this plate is processed with a plate around the periphery of the dome, thus the stress will evenly distribute on the plate, as indicated by the upward arrows on the figure. The contact area between steel belt and plate is face contacted, the penetration through the steel belt is unlikely to occur. If the surrounding rock mass deforms and the deformation continues, the load will continuously transfer from bolt to the face plate, then from face plate to steel belt, and afterwards from steel belt to surrounding rock mass.

\section{HUMID COAL MASS LOWERING BONDING EFFECTS IN BOLTING SYSTEM}

Field observation has proved that water leaching/spilling always can be noticed in some locations, especially for roof strata, and a lot of premature failures of bolting system can also be noticed, some examples are selected and listed in Fig. 8.

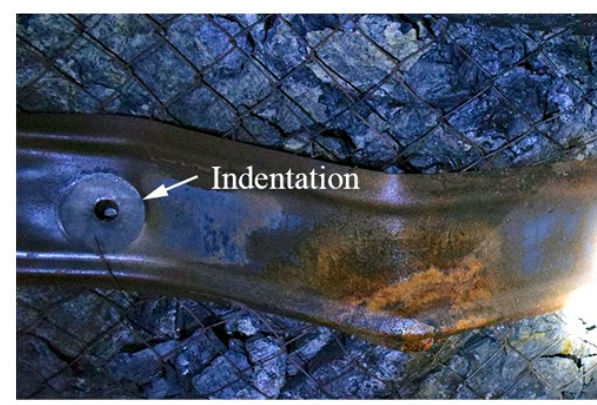

(a)

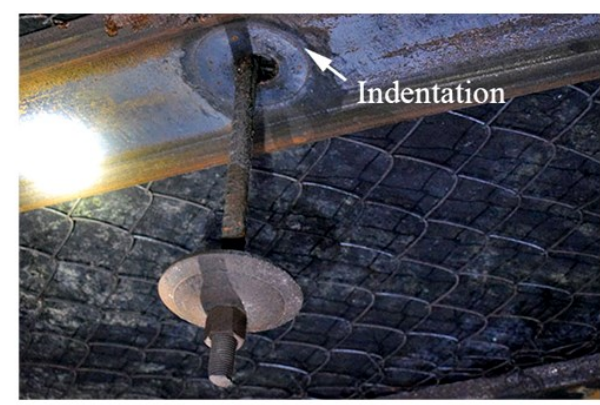

(b)

Fig. 8 Failures of bolting system, (a) bolting components disappears, (b) fall off of bolt altogether with face plate and nut

In Fig. 8a, bolt, face plate and nut disappears from the roof, leaving steel belt contacts loosely with roof. An obvious indentation can be noticed on the surface of steel belt, which was caused by the compressional force between face plate and steel belt during pretension process or by roof's subsidence. In Fig. 8b, the 
bolting component falls off from the borehole and hangs on the roof. Obviously the bolt in such a state provides no reinforcing effects to the roof strata. It is very likely that some mechanical interactions between bolt and borehole wall sustain the dead weight of the bolting component, either by friction or horizontal shearing of strata. Similarly, an indentation is also observable on the steel belt. In view of the existence of indentation on the steel belt, it can be concluded that there must existed a period before the detachment that the face plate had a good contact with the steel belt and even certain value of loading was sustained between them. With the passage of time, roof deformation aggravated and which caused load rising of bolting system, eventually it should have been the penetration of face plate that failed the system if the thin thickness of belt was considered, as has been formerly stated in section 4.1. However, the true situation is the popup or fall off of the whole bolting component (Fig. 8), leaving a shallow indentation on the steel belt.

Based on reverse inference, it is very sure that the axial load on the bolt was quite low before failure because the system's bearing capacity was determined by the anti-penetration capacity of the steel belt, as previously demonstrated. Therefore the improper stirring of resin during installation could be one main inducement, and the low bonding strength at the interface between resin and borehole wall should be another inducement. The first inducement can be largely avoided as long as the installation procedure is regulated and proper rules for 'spin and hold' or 'spin to stall' is followed. The second inducement is mainly connected with the environment inside the borehole. It has been commonly acknowledged that the mix of the two components inside epoxy resin cartridge will be greatly weakened in humid environment -(Zhang et al. 2011). Field observation has confirmed the water spilling/leaching property of coal mass, hence the failure of bolting system was caused by weak bonding force between resin annulus and borehole wall due to the existence of water. Once the bolts were loaded and roof's deformation continued, decoupling would eventually occur inside bolting system then further led to popup or fall off of bolt. Therefore, cement grouting measure is suggested at sections where the humidity is high.

\section{Isolation between support zones of rock bolts and cable bolts}

Coal mine practitioners selected cable bolt and rock bolt to reinforce strata inside the coal mass, and this measure is always effective and reasonable based on numerous successful trials all around the world not only in coal mine application but also in civil, hydraulic and slope deformation controlling areas. Nonetheless, wise choice of parameters do matter a lot.

In Fujiaao coal mine, the length for cable bolt is $8200 \mathrm{~mm}$ and the diameter is $17.8 \mathrm{~mm}$ whilst corresponding values for rock bolt are $2000 \mathrm{~mm}$ and $20 \mathrm{~mm}$, respectively. Then the negative effects can be analyzed from two aspects. The first one is the isolation between support zones of rock bolts and cable bolts; the second one is the long time costed on drilling process for $8200 \mathrm{~mm}$ long borehole, normally installing one cable bolt can cost approximate one hour. 
Technically speaking, elongation ratios for cable bolt (0.03) and rock bolt (0.2) are totally different, therefore their elongation value under identical load will also different, which further leaves opportunity to strata to deform to accommodate such a confliction. Furthermore, it has been widely acknowledged that roof's subsidence is a progressive procedure which initially only occurs at the shallow depth and then mitigates to the far distance to the excavation. As a result, there should exist a period when the function of cable bolt is limited or the function of cable bolt is limited, depending on which one carries the roof's load firstly. In Fig. 9, hereinbefore illustrated mechanism is schematically drawn, in which the length of the double arrowed line indicates the value of sustained load.
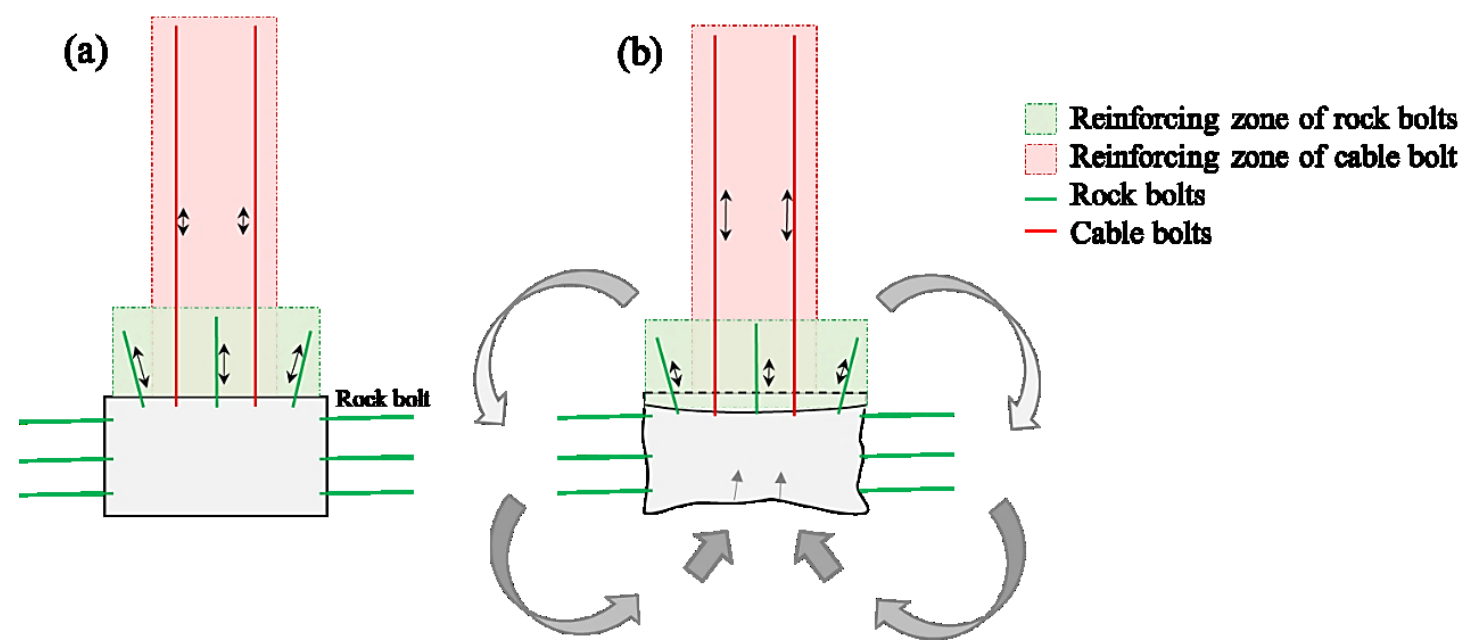

Fig. 9 Schematic sketch of reinforcing zones isolation between rock bolts and cable bolts

Fig. 9a portrays an early state of the entry with no deformation of coal mass expressed. Considering the progressive deformation procedure and the elongation confliction illustrated above, in the very beginning, only rock bolts are sensitive to roof's subsidence and therefore can be loaded, cable bolts at this time are barely loaded due to overlarge elongation ratio gap with rock bolts. However, as subsidence aggregates, the fracture of roof strata will penetrate to the deep area and then activate the reinforcing effects of cable bolts (Fig. 9b). Though cable bolts can be loaded at later stage, the breakage of roof strata has already transferred into the deep areas. As a results, roof strata drops to the floor as an integrity with cracks abundantly distributed inside, especially for the rock bolts reinforcing zone. Roof strata at this moment already loses its selfsupporting ability (Frith et al. 2018), the dead weight is largely sustained by cable bolts, causing a formation of cable reinforcing zone. Then the stress will transfer bilaterally to ribs and lead to ribs bulking, eventually stress will transfer from ribs to floor, leading to severe floor heave problem (Mo et al. 2019). Former procedure is sketched in Fig. $9 \mathrm{~b}$.

In Fig. 10, approximate D-L relationship for rock bolt, overlong cable bolt and cable bolt with proper length is plotted. Under specific deformation of surrounding coal mass, the load of overlong cable bolt is the smallest, indicating an insufficient reinforcement to strata. Whilst if the cable bolt length is 
approximate, it's bearing capacity will be approximately equal to rock bolt, therefore a synergetic reinforcement can be achieved.

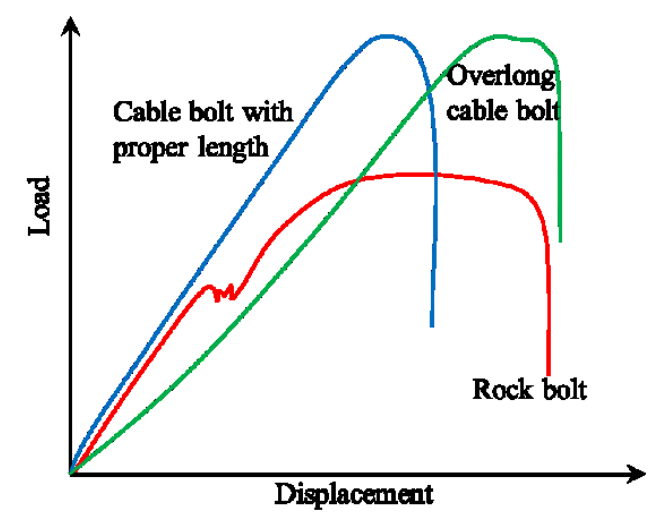

Fig. 10 Approximate D-L relationship for rock bolt, overlong cable bolt and cable bolt with proper length

\section{Low conversion rate between pretension force and axial force}

For all rock bolts and cable bolts installed in the entries, certain pretension force was applied on the tendons to guarantee the active reinforcing effects to strata. However, field observation reveals that the active reinforcing effect is rather limited, as can be seen by the values of pressure gauges.

Fig. 11 gives two examples and similar ones are too many too be listed here, it can be seen that values both for rock bolt (left one) and cable bolt (right one) are quite low (no more than $10 \mathrm{kN}$ ). Regardless of the loading impacts from roof's deformation, these readings are extremely low compared with required values that indicate approximate pretension force. Take $18 \mathrm{~mm}$ diameter bolt for example, the pretension force should at least reach $70 \mathrm{kN}$ or more to attain pretension effect. Moreover, the whole systems in Fig. 11 show no sign of failure at any component.

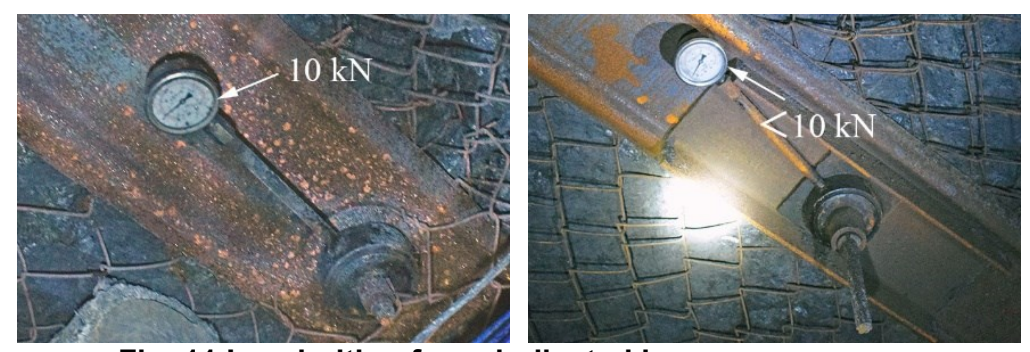

Fig. 11 Low bolting force indicated by pressure gauge

Actually, practitioners utilized torque wrench to apply pretension force. However, as can be seen, all of the bolts were not equipped with a washer between nut and face plate (Fig. 6a,b). The washer is very important and can greatly increase the transfer efficiency between applied torque on the nut and axial force along the bolt (Kang et al. 2016). As for cable bolt, the pretension force is applied by tension procedure, an insufficient tensile capacity should be one of the main reason leading to the low pretension force of cable bolts. 


\section{CONCLUSION}

In this study, field observation is conducted in a coal mine and some new insights are proposed to deepen the understanding of coal mine support methodology. Altogether four factors are took into consideration like strength mismatch in bolting system, impacts of humid coal mass on stability of bolting system, isolation between cables' supporting zone and bolts' supporting zone, and lastly, the low conversion rate between pretension force and axial force. It should be emphasized that coal mine practitioners should take wise consideration before selection of supporting components. Oftentimes the bolting system can be failed not because of the strength of the bolt itself but because of its assorted components. As a whole, suggestions are established in this study. Such as proper choice of face plate to expand supporting strength to coal mass, full consideration of coal mass humidity and consider grouting approach if the humidity is high, approximate cables' length to connect cables' supporting zone and bolts' supporting zone, and selection of high-conversion rate washer to meet high axial pretension (active support).

\section{REFERENCES}

Aziz, N., Craig, P., Mirzaghorbanali, A., et al (2016). Factors Influencing the Quality of Encapsulation in Rock Bolting. Rock Mechanics and Rock Engineering, 49, pp. 3189-3203.

Frith, R., Reed, G. and McKinnon, M. (2018). Fundamental Principles of an Effective Reinforcing Roof Bolting Strategy in Horizontally Layered Roof Strata and Areas of Potential Improvement. International Journal of Mining Science and Technology, 28, pp. 67-77.

Kang, H., Wu, Y., Gao, F., et al (2013). Fracture Characteristics in Rock Bolts in Underground Coal Mine Roadways. International Journal of Rock Mechanics and Mining Sciences, 62, pp. 105-112.

Kang, H., Wu, Y., Gao, F., et al (2016). Mechanical Performances and Stress States of Rock Bolts Under Varying Loading Conditions. Tunnelling and Underground Space Technology, 52, pp. 138-146.

Li, CC., (2010). Field Observations of Rock Bolts in High Stress Rock Masses. Rock Mechanics \& Rock Engineering, 43, pp. 491-496.

Mo, S., Tutuk, K. and Saydam, S. (2019). Management of Floor Heave at Bulga Underground Operations - A Case Study. International Journal of Mining Science and Technology, 29, pp. 73-78.

Zhang, N., Wang, C., Xu, XL., et al (2011). Argillisation of Surrounding Rock Due to Water Seepage and Anchorage Performance Protection. Materials Research Innovations, 15, pp. 582-585. 
Abstract.

In this paper, field observation is conducted in Fujiaao Coal Mine, Linfen city in Shanxi province, China, which is unique because of its island-typed mining layout. Firstly, geology, layout of the coal cutting face, supporting pattern are presented and details are also provided. Then the problems are discussed and analyzed based on existing bolting theories. It finds out the length of the cable bolt is too long, which requires long time to drill boreholes, whilst the effectiveness is limited due to the illogical combination between cable bolt function zone and rock bolt function zone. Also, the face place allocated to rock bolt is very likely to cause line contact between its edge and steel belt, thus the bearing force is tremendously weakened and solely determined by strength of belt. Furthermore, field observation proves the low active supporting effects to roof, thus leading obvious roof sink even without the disturbance of mining activity. Eventually, some solutions are proposed with the intention to improve the situation based on the economic and technical considerations, including bolting in humidity environment, rational cable bolt length, wise choice of face plate, and ways to increase pretension force. The viewpoints and comments of this study can be referred by practitioners in coal mines sharing same difficulties.

Keywords: coal mine support, bolt, support optimization, field observation, support failure 